\title{
A NOTE ON THE BARNACLE LARVAE OF THE CLYDE SEA AREA AS SAMPLED BY THE HARDY CONTINUOUS PLANKTON RECORDER
}

\author{
By H. Barnes \\ The Marine Station, Millport
}

In the course of an extensive series of tests on the Hardy Continuous Plankton Recorder (Hardy, I939) carried out in the Clyde Sea Area during March and April I949, a number of runs were made both during the time of the spring diatom outburst and over the period when barnacle larvae were a dominant feature of the zooplankton. It should be emphasized that the work was originally planned not as a plankton study but only as an investigation of the comparative performance of a number of recorders. Nevertheless, the limited data on cirripede larvae do give some quantitative information regarding the distribution and the total population of barnacle larvae over a moderately large area, and the quantitative relations of the stages, as well as providing some evidence bearing upon the hypothesis that the diatom outburst is a controlling factor in the development of the later stage larvae.

Since the results of these tests have not yet been published the following points regarding the performance of these recorders may be mentioned:

(I) The excellent depth-keeping properties of the machines have been fully confirmed; a constant depth of $10 \pm 0.5 \mathrm{~m}$. was maintained over long distances by both machines under test.

(2) The amount of water filtered is probably the theoretical volume, since great increase in filtering surface (obtained by fitting large nets inside the machines) gave no significant increase in catch. This was true even with clogging which became apparent during the diatom outburst. It should, however, be remembered that the diatom was largely Skeletonema costatum; quantities of larger phytoplankton species could lead to incomplete filtration.

Thanks are due to $\mathrm{Mr} \mathrm{W}$. W. Brown who took part in the recorder investigations, to $\mathrm{Mr} \mathrm{M}$. W. H. Bishop for confirming the identity of the larval stages counted, and to Captain Stewart and the crew of the Calanus for their willing help in all the boat work.

\section{The Collection and Counting of the Material}

The plankton recorders were towed together in pairs under varying experimental conditions, and a statistical examination of the results has shown that in none of the tows here quoted was there any significant difference in the performance of the two machines. In Table I, therefore, only the mean catch 
Table I. Cirripede Larvae from the Clyde Sea Area Population, Early Spring i949; TOTAL CATCHES AND THEIR COMPOSITION

\begin{tabular}{|c|c|c|c|c|c|c|c|c|c|c|c|c|c|c|c|c|}
\hline \multirow{3}{*}{$\begin{array}{l}\text { Date } \\
\text { 2r. iii. } 49\end{array}$} & \multirow{3}{*}{ Run } & \multicolumn{2}{|c|}{$\begin{array}{l}\text { Total catch } \\
\text { cirripede larvae }\end{array}$} & \multicolumn{7}{|c|}{$\begin{array}{l}\text { The percentages stages, (i) B. balanoides, } \\
\text { (ii) } B \text {. crenatus from subsample counts }\end{array}$} & \multicolumn{6}{|c|}{ Estimated numbers in original sample } \\
\hline & & Nauplii & Cyprids & & Cyprids & VI & V & IV & III & $\mathrm{II}+\mathrm{I}$ & Cyprids & VI & V & IV & III & $\mathrm{II}+\mathrm{I}$ \\
\hline & & I839 & $6)$ & (i) & 0.2 & $3 \cdot 4$ & $7 \cdot 3$ & 9.6 & $36 \cdot 3$ & I 4.4 & 4 & 62 & 132 & I 74 & 657 & $26 \mathrm{I}$ \\
\hline & 3 & 1776 & o) & (ii) & 0.6 & $\mathrm{I} \cdot \mathrm{I}$ & $7 \cdot 3$ & $5 \cdot 2$ & $7 \cdot 8$ & $1 \cdot 6$ & II & 20 & 132 & 94 & I4I & 29 \\
\hline & 4 & I4I 8 & 5 & (i) & 0.9 & $4 \cdot 6$ & I6.4 & 14.5 & $34 \cdot 6$ & $17 \cdot 3$ & I3 & 66 & 233 & 206 & 492 & 246 \\
\hline & & & & (ii) & 0.0 & $3 \cdot 3$ & $2 \cdot 3$ & I. 4 & I.9 & I.9 & 0 & 47 & 33 & 20 & 27 & 27 \\
\hline & 5 & 2230 & I4 & (i) & 0.2 & $5 \cdot 1$ & $I 6 \cdot 4$ & 19.3 & 29.9 & $9 \cdot 2$ & 5 & II 4 & 368 & 433 & 671 & 207 \\
\hline & & & & (ii) & 0.1 & $4 \cdot 6$ & $5 \cdot 3$ & $3 \cdot 4$ & $2 \cdot I$ & 0.7 & 2 & 103 & II9 & 76 & 47 & I6 \\
\hline 22. iii. 49 & 6 & I5O4 & 2 & (i) & 0.4 & $3 \cdot 2$ & 13.8 & II. 5 & $39 \cdot 6$ & $14 \cdot 3$ & 6 & 48 & 208 & I73 & 596 & 215 \\
\hline & & & & (ii) & 0.0 & $5 \cdot 1$ & I.9 & 6.5 & I. 4 & $O \cdot I$ & 0 & 77 & 29 & 98 & $2 I$ & 2 \\
\hline & 7 & I337 & 3 & (i) & 0.4 & I.9 & 13.0 & $12 \cdot 2$ & 30.5 & I $7 \cdot \mathbf{I}$ & 5 & 26 & 174 & I64 & 409 & 229 \\
\hline & & & & (ii) & 0.0 & $7 \cdot 4$ & $5 \cdot 2$ & $6 \cdot 3$ & 3.5 & 0.7 & 0 & 99 & 70 & 84 & 47 & 9 \\
\hline 23. iii. 49 & 8 & I 848 & Io & (i) & 0.7 & $3 \cdot 3$ & 12.8 & $24 \cdot I$ & $34 \cdot 8$ & II I I & 13 & $6 I$ & 238 & 448 & 647 & 206 \\
\hline & & & & (ii) & 0.0 & $\mathrm{I} \cdot 9$ & I'9 & $2 \cdot 2$ & I. 4 & $O \cdot I$ & 0 & 35 & 35 & $4 \mathrm{I}$ & 26 & 2 \\
\hline & 9 & 2886 & 27 & (i) & 0.2 & $2 \cdot 8$ & 12.7 & $27 \cdot 8$ & $28 \cdot 7$ & $5 \cdot 7$ & 6 & 82 & 370 & 810 & 836 & 166 \\
\hline & & & & (ii) & 0.0 & $6 \cdot 4$ & $5 \cdot 3$ & $5 \cdot 3$ & I. 7 & 0.2 & 0 & I86 & I54 & I 54 & 50 & 6 \\
\hline & Io & 2959 & 27 & (i) & 0.2 & $2 \cdot 6$ & $7 \cdot 5$ & $27 \cdot 5$ & $24 \cdot 2$ & $10 \cdot I$ & 6 & 78 & 224 & 821 & 723 & 302 \\
\hline & & & & (ii) & 0.4 & $5 \cdot 2$ & $4 \cdot 2$ & $5 \cdot 4$ & $6 \cdot 3$ & $2 \cdot I$ & 12 & I55 & 125 & I6I & I88 & 63 \\
\hline & II & 3633 & 46 & (i) & 0.3 & 3.0 & 8.6 & $24 \cdot I$ & $24 \cdot I$ & $9 \cdot 6$ & II & IIO & 316 & 887 & 887 & 353 \\
\hline & & & & (ii) & 0.8 & $7 \cdot 5$ & $5 \cdot 3$ & $8 \cdot 4$ & $5 \cdot I$ & $I \cdot I$ & 29 & 276 & 195 & 309 & I88 & 40 \\
\hline 4. iv. 49 & 12 & 2717 & I888) & & & & & & & & & & & & & \\
\hline & 13 & 2064 & I 472 & (i) & $26 \cdot 9$ & 19.5 & $8 \cdot 7$ & 4.5 & I. 4 & 0.7 & 895 & 649 & 289 & 150 & 47 & 23 \\
\hline & I4 & I650 & ror9 & (ii) & $10 \cdot 0$ & $5 \cdot 3$ & 5.6 & I.9 & 0.6 & 0.3 & 338 & 176 & 186 & 63 & 20 & I0 \\
\hline & I5 & I326 & I I 69) & & & & & & & & & & & & & \\
\hline 5. iv. 49 & I6 & I674 & I475! & (i) & $42 \cdot 8$ & 10.9 & $4 \cdot 8$ & $I \cdot 6$ & 0.6 & 0.1 & 1563 & 398 & 175 & 58 & 22 & 4 \\
\hline & 17 & 2117 & 2036 ; & (ii) & I6.8 & 4.5 & $4 \cdot 6$ & 0.6 & 0.3 & 0.0 & 613 & I64 & 168 & 22 & II & 0 \\
\hline
\end{tabular}


for the two machines on any given run is shown (columns 3 and 4 ). The recorders were run at their 'standard' depth of $10 \mathrm{~m}$. The duration of each tow was half an hour at a speed of 8 knots (nominal), so that, neglecting the effect of tidal currents and wind, 4 nautical miles of water were filtered through the standard $\frac{1}{2} \times \frac{1}{2}$ in. nozzle, a total of I. 2 cu.m. of water per haul.

The area sampled extended from the north end of the Largs Channel to a point some 8 miles farther south, off the Little Cumbrae Island, the channel between the islands and the mainland being approximately I mile wide throughout this distance. The particular position of any run was not noted, the choice being dictated by considerations of convenience as regards the major project, namely the testing of the plankton recorders. The samples, therefore, although not random in the statistical sense, are probably representative of the conditions over this particular area.

For the purpose of all these tests the propellers of the machines were removed; in some the gauze remained stationary across the tunnel, whilst in others the inside mechanism was removed and a small net attached at the inner end of the fore part of the water tunnel. At the termination of each run the gauze both over the tunnel and for some distance on either side was cut out and, together with the catch, transferred to a breffit containing formalin; if a net had been used inside the recorder, it was carefully removed and the contents washed by means of a wash-bottle into a breffit.

The whole catch was first counted without sub-sampling, the barnacle larvae being recorded as nauplii and cyprids irrespective of stages or species; the mean catches per run for the two machines are shown in columns 3 and 4 of Table I. The catches were then subsampled (some after pooling several samples) by Russell \& Colman's technique (I93I), and the number of the various stages of Balanus balanoides (Linn.) and B. crenatus Brug. counted in each subsample (one-tenth of the total catch). The percentages of these stages as determined from the counts of such subsamples are shown in columns 5-IO. An estimate of the actual numbers of the various stages present in the original sample (single or pooled) was then calculated from these percentages and the mean value of the total number in the original sample or samples, and these estimates are given in columns II-I6.

The 'standard' gauze (60 mesh) was used in the recorders, and a microscopic examination of such gauze showed the holes to be approximately square and between 0.2 and $0.25 \mathrm{~mm}$. in cross-section. Pyefinch (I948a) gives the full length of Nauplius I as $0.34 \mathrm{~mm}$. in B. balanoides and $0.28 \mathrm{~mm}$. in $B$. crenatus, while from his diagrams the carapace width of this stage in its widest part is slightly less than $0.25 \mathrm{~mm}$. for the former, but only $0.15 \mathrm{~mm}$. for the latter. Stage II of B. balanoides is given as $0.54 \mathrm{~mm}$. full length and from the diagram $0.35 \mathrm{~mm}$. carapace width, whilst Stage II of B. crenatus, which is rather more slender, is $0.44 \mathrm{~mm}$. long and about $0.25 \mathrm{~mm}$. greatest width. It would appear, therefore, that with the gauze used in these experi- 
ments there is some chance that Nauplius I of both B. balanoides and B. crenatus and possibly Nauplius II of the latter were not caught quantitatively. It must, however, be remembered that the effective width of the animal is increased by the presence of appendages. Further, during many of these runs diatoms were very abundant, and considerable clogging of the gauze resulted; in these circumstances the effective opening of the gauze would be reduced and any loss of the earlier naupliar stages to some extent prevented.

\section{The Weather and Hydrographic Conditions}

During the course of all these collections and throughout the whole of the period covering the spring diatom outburst the weather was good. Winds, in general from the south-west, were moderate, the mean speed from I6th to 3Ist March being Io m.p.h. The wind freshened during the first few days of April (I9 m.p.h.). The daily surface sea temperatures (mean $7.53^{\circ}$ C.) were rather higher than the average and varied only from $7 \cdot 2$ to $7 \cdot 8^{\circ} \mathrm{C}$. during this period, whilst the salinity, $3 \mathrm{I} \cdot 5 \%$, was normal for this period. The upper layers of the water at this time are homothermal, with consequent considerable

\begin{tabular}{|c|c|c|}
\hline & $\begin{array}{c}\text { I948-49 } \\
\left({ }^{\circ} \mathrm{C} .\right)^{-1}\end{array}$ & $\begin{array}{c}\text { Io-year mean } \\
\left({ }^{\circ} \mathrm{C} .\right)\end{array}$ \\
\hline November & 10.6 & IO. I \\
\hline December & $9 \cdot 4$ & $8 \cdot 4$ \\
\hline January & 7.9 & $7 \cdot 3$ \\
\hline February & $7 \cdot 4$ & $6 \cdot 6$ \\
\hline March & $7 \cdot 2$ & 6.9 \\
\hline April & 8.2 & $7 \cdot 2$ \\
\hline
\end{tabular}

vertical mixing, so that hauls at $\mathrm{IO} \mathrm{m}$. may reasonably be considered as representative.

In view of the extraordinary barnacle settlement, one of the heaviest for many years, it is of interest to record that throughout the winter and during the spring the sea temperatures (surface values) had been considerably higher than normal (Table II).

\section{The Distribution of Larvae in Space and Time}

The results set out in Table I indicate that over the whole area and over a considerable period of time the population of barnacle larvae showed no enormous fluctuations. Considering the catches of total larvae as separate samples of the larval population of the whole area sampled there is no significant difference between the means of the catches on the first 2 days (analysis performed on logarithmic values of catches), $t=\mathrm{I} \cdot 568, n=4, P=0.2$; there is a significant difference between the first two and the third day, $t=3.505, n=8$, $P=0.02-0.01$; but no significant difference between the third day and the last 
2 days, $t=\mathrm{I} \cdot \mathrm{I0}, n=8, P=0.3$. The mean for the first 2 days was I689 larvae and the mean for the rest of the period was 3204 larvae.

The population and its composition over the area was remarkably constant on some of the days. Since each traverse extended 4 miles, the off-shore population even if made up of small swarms would be adequately sampled.

An analysis of variance for the first day, neglecting the cyprids since they were present in very small numbers, is given in Table III.

\section{TABLE III}

$\begin{array}{cccc}\begin{array}{c}\text { Source of } \\ \text { variation } \\ \text { Main effects: }\end{array} & \begin{array}{c}\text { Degrees of } \\ \text { freedom }\end{array} & \begin{array}{c}\text { Sum of } \\ \text { squares }\end{array} & \begin{array}{c}\text { Mean } \\ \text { square }\end{array} \\ \text { Hauls (H) } & 2 & 0.2731 & 0.1366 \\ \text { Species (Sp) } & \mathrm{I} & 3.4476 & 3.4476 \\ \text { Stages (St) } & 4 & 0.931 \mathrm{I} & 0.2328 \\ \text { First-order interactions: } & & & \\ \text { H } \times \text { Sp } & 2 & 0.1748 & 0.0874 \\ \mathrm{H} \times \mathrm{St} & 8 & 0.5384 & 0.0673 \\ \text { Sp } \times \text { St } & 4 & 0.7334 & 0.1834 \\ \text { Second-order interaction: } & & & \\ \text { H } \times \text { Sp } \times \text { St } & 8 & 0.3120 & 0.0390 \\ \text { Total } & 29 & - & -\end{array}$

The mean square for $\mathrm{H} \times \mathrm{Sp}$ and $\mathrm{H} \times \mathrm{St}$ are not significant when tested against $\mathrm{H} \times \mathrm{Sp} \times \mathrm{St}$. The values may be pooled giving a new residual of 0.0570 (I8 degrees of freedom); and the value for hauls is not significant. There is therefore no significant difference between the hauls, and no significant difference between the proportion of species and stages in the hauls.

For the second day the analysis of variance is given in Table IV.

TABLE IV

$\begin{array}{lccc}\begin{array}{c}\text { Source of } \\ \text { variation }\end{array} & \begin{array}{c}\text { Degrees of } \\ \text { freedom }\end{array} & \begin{array}{c}\text { Sum of } \\ \text { squares }\end{array} & \begin{array}{c}\text { Mean } \\ \text { square }\end{array} \\ \begin{array}{l}\text { Main effects: } \\ \text { Hauls (H) }\end{array} & \text { I } & 0.0433 & 0.0433 \\ \text { Species (Sp) } & \text { I } & 2.3318 & 2.3318 \\ \text { Stages (St) } & 4 & 1.0856 & 0.2714 \\ \text { First-order interactions: } & & & \\ \text { H } \times \text { Sp } & \text { I } & 0.1868 & 0.1868 \\ \text { H } \times \text { St } & 4 & 0.1126 & 0.0282 \\ \text { Sp } \times \text { St } & 4 & 2.6738 & 0.6685 \\ \text { Second-order interaction: } & & & 0.0559 \\ \text { H } \times \text { Sp } \times \text { St } & 4 & - & - \\ \text { Total } & \text { I9 } & & \end{array}$

Again $\mathrm{H} \times \mathrm{St}$ mean square is not significant, but at the $5 \%$ level the $\mathrm{H} \times \mathrm{Sp}$ mean square is significant. The value for the hauls is not significant. The proportion of the species therefore varied during the hauls, although the 
proportion of the stages remained unchanged. However, on the third day, although $\mathrm{H} \times \mathrm{St}$ is not significant the value for $\mathrm{H} \times \mathrm{Sp}$ is high, indicating considerable variation in the proportions of the species in the hauls. The analysis of variance is given in Table $\mathrm{V}$.

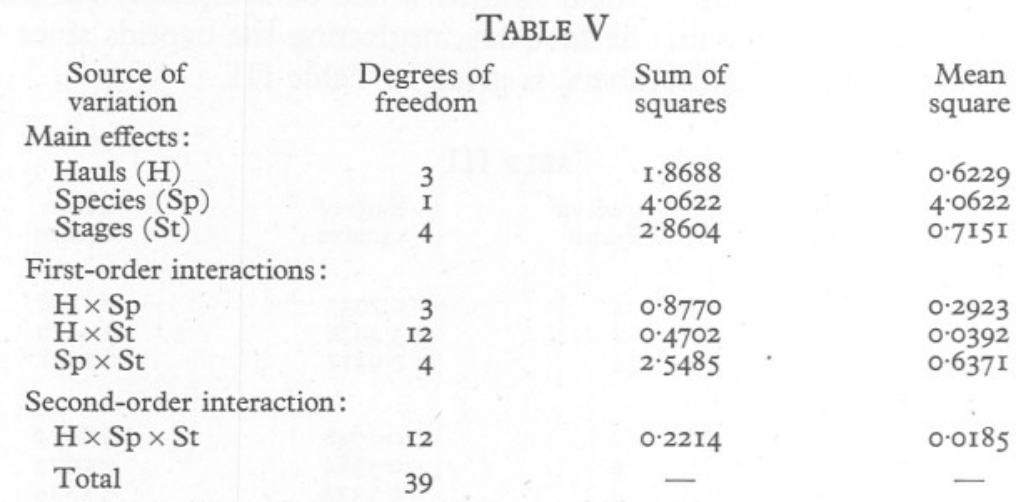

The wide day-to-day fluctuations often reported may be due to sampling techniques and also, particularly in respect of Stages I and II nauplii, to the effect of the abundant supply of parent stock when sampling is effected by nets attached to fixed inshore structures.

\section{The Barnacle Larvae Population}

It was found as a result of the present tests that in spite of such diatom clogging as was apparent at the time, the plankton recorders filtered the theoretical quantity of water. It is, therefore, possible to obtain an accurate estimate of the barnacle population, although such an estimate suffers from the disadvantage that nothing is known of the vertical distribution of the population.

The mean number of larvae per haul over the whole period is 2636 and this is taken in $\mathrm{I} \cdot 2$ cu.m. which gives 2197 larvae per cu.m. Pyefinch (I948b) gives I3,644 as the highest average daily haul for a single month. Now this figure was obtained with a $50 \mathrm{~cm}$. net fished for I hr. under conditions which do not permit quantitative deductions. However, at a tidal speed of I knot the theoretical volume filtered is approximately 350 cu.m. of water per hour. Such a comparison suggests either that nets fished on the tide in this manner are not fishing effectively, or that the larval populations here recorded were very much higher than those previously recorded.

It is of some interest to calculate an approximate estimate of the total barnacle larvae population for the whole of this body of water. If it is assumed that the larvae were uniformly distributed down to a depth of $\mathrm{I} 0 \mathrm{~m}$., a reasonable assumption in view of the vertical mixing at this time of the year, and taking the area to be approximately 8 square miles and using the above value for the mean population density, the number of larvae is of the order of $6 \times 10^{11}$. 
The Relation of the Stages

Pyefinch (I948b), Johnstone, Scott \& Chadwick (I924), and Fish (I925) consider that between the Stages I and II Nauplii and the cyprid stage there is a considerable depletion of the population, although no cause is suggested. According to Pyefinch the interval between Nauplius III and the cyprid stage is of the order of I5-2I days. In the present instance such a developmental period would mean that all the barnacle larvae from Stage III to cyprids present in the first runs (2I March) should have appeared as cyprids by the time the run was taken on 5 April. Taking the higher population of the 23 rd to represent this earlier stage of the population, the mean number of III to cyprid stages was I894 and 580 for $B$. balanoides and B. crenatus, respectively. On 5 April the corresponding catches were $\mathrm{I}_{5} 63$ and 6I4. This does not indicate any depletion of stock between Stage III and cyprid. It is possible that the depletion takes place between Stages I + II and III (on this point the data give no information), but it is suggested that the apparent depletion may be due to the fact that in taking samples off in-shore structures, as was done by Pyefinch and Fish, the numbers of Stages I and II are not representative of the planktonic content of the whole body of water. The catches of these two stages will be grossly influenced by the close proximity of the parent stock. It is also perhaps significant in this connexion, that Pyefinch found this discrepancy less for $B$. crenatus, a sublittoral species, and that his figures also show a much less discrepancy when the Stage III and cyprid populations are compared for $B$. balanoides. Johnstone et al. took their samples in the in-shore waters across Port Erin Bay and the proximity of parent stock may be partially responsible for the apparent discrepancy. Also it is to be noted that, according to the catches of these workers, there is a great increase in the diatom population at the time the cyprids were being caught; clogging of their nets may have resulted in the filtration of less water than was filtered when nauplii were the main larval stage present, under which circumstances more water would be filtered when the earlier stages were being sampled. Development takes place over a period of approximately I month, during which considerable dispersion of the larvae takes place (as indicated by the above results) so that the whole body of water should be sampled for the stages in order to compare any changes within the population. Further, the above results suggest that there is no reason to assume, as does Pyefinch, either that the cyprids tend to occur in greater numbers in-shore, or that they would become more abundant in in-shore waters later in the tide.

\section{The Effect of Diatoms on the Larval Development}

It has been maintained by Pyefinch (I948 b) that the development of the later stages of the nauplii and the production of cyprids is considerably interfered with by a heavy diatom population. This does not seem to be true in the present series. On I6 March few diatoms were present, but the spring outburst of 
Skeletonema costatum began between the I6th and 2Ist of that month, reached its maximum between the 22 nd and 25 th and was virtually over by the 3 Ist. A lack of records does not allow speculation before the diatom outburst took place, but it is clear that development from Stage III to cyprids was never interfered with by the diatom outburst, since this is the period over which it has been shown that the earlier nauplii stages completed their development with the production of the 'corresponding' number of cyprids. That cyprid development took place is substantiated by the fact that settlement on the shore was first observed on 3 April (35-40 newly settled cyprids per sq.in.) and that there subsequently developed one of the heaviest settlements which has been seen in this area for a number of years. A non-toxic panel exposed on a raft in-shore during this period (in connexion with another investigation) and withdrawn on I5 April had 23I (mean of four separate counts) barnacles of less than I mm. in size per sq.in.

\section{SUMMARY}

A series of results is presented on the barnacle larvae population of an area of the Firth of Clyde, over a I5-day period in the spring taken by means of a modified Hardy Plankton Recorder.

The records and observations on barnacle settlement indicate that the larval population was considerably greater than usual.

The total larval population showed no great fluctuations from day to day, and on a given day the composition of the population over a wide area was often reasonably constant.

Evidence is presented that there is no great depletion of the population between Nauplius III and cyprid stages. It is suggested that the depletion previously reported may be due in part to the method of sampling or to the conditions at the time of sampling.

During the time when the evidence indicates no depletion of population there was a heavy diatom outburst, which in this instance did not appear to interfere with the larval development.

Data are given on the density of settlement.

\section{REFERENCES}

Fish, C. J., I925. Seasonal distribution of the plankton of the Woods Hole Region. Bull. U.S. Bur. Fish. Washington, Vol. 4I, pp. 9I-I79.

HARDY, A. C., I939. Ecological investigations with the Continuous Plankton Recorder: object, plan and methods. Hull. Bull. Mar. Ecol., Vol. I, No. I, pp. I-57.

Johnstone, J., Scott, A. \& Chadwick, H. C., I924. The Marine Plankton. London. Pyefinch, K. A., I948 a. Methods of identification of the larvae of Balanus balanoides (L.), B. crenatus Brug. and Verruca stroemia O. F. Müller. Fourn. Mar. Biol. Assoc., Vol. 27, pp. 45I-63.

- 1948b. Notes on the biology of cirripedes. Fourn. Mar. Biol. Assoc., Vol. 27, pp. 464-503.

Russell, F. S. \& Colman, J. S., I93I. The Zooplankton. I. Gear, methods and station lists. Great Barrier Reef Exp. I928-9, Sci. Rep., Vol. 2, pp. 5-35. 